The development and preliminary testing of a scale to measure the latent and manifest benefits of employment

\author{
Muller, J. J. \\ Centre for Work, Leisure and Community Research \\ and School of Psychology \\ Griffith University - Logan Campus \\ Meadowbrook, Queensland, Australia, 4131 \\ j.muller@griffith.edu.au \\ Creed, P. A. \\ Service Industry Research Centre \\ and School of Psychology \\ Griffith University - Gold Coast Campus \\ PMB 50, Gold Coast Mail Centre, Queensland, Australia 9726 \\ Waters, L.E. \\ Department of Management \\ The University of Melbourne \\ Parkville, Victoria, Australia, 3010 \\ Machin, M.A. \\ Department of Psychology, \\ University of Southern Queensland \\ Toowoomba, Queensland, Australia 4350
}




\title{
The development and preliminary testing of a scale to measure the latent and manifest benefits of employment
}

\begin{abstract}
Theorists have argued the importance of the latent and manifest benefits of employment and their relationship with psychological well-being. However, no one scale has been devised that adequately and reliably measures all five latent and one manifest benefit together. The aims of this study were to develop such a scale that satisfies standards for psychometric adequacy, and to present evidence for its validity. In the scale development phase, in-depth interviews with 33 unemployed adults and comments from labour market experts were used in the item generation process. In Study 1, 307 unemployed adults were surveyed, and item analysis, inter-item and item-total correlations and factor analysis were used to reduce the item pool to a 36-item scale, with six homogenous and reliable subscales. In Study 2, 250 unemployed adults were surveyed and the scale was subjected to confirmatory factor analysis and tested for associations with psychological distress, neuroticism and various demographic variables. As a result, a reliable and valid 36-item Latent and Manifest Benefits (LAMB) scale was developed. Implications for use in research are discussed.
\end{abstract}

Keywords: Latent benefits, manifest benefits, unemployment, Jahoda, Fryer, access to categories of experience 
The negative psychological and health costs of unemployment have now been well established (see Murphy \& Athanasou, 1999). Two of the most widely accepted theories in the unemployment literature explaining the negative effects of unemployment are Jahoda's (1981) latent deprivation model and Fryer’s (1986) agency restriction model. Jahoda argued that it was the loss of five latent benefits of employment (time structure, activity, social contact, collective purpose, and status) that accounted for psychological distress. Past research has demonstrated a positive relationship between access to the latent benefits and psychological well-being (Creed \& Macintrye, 2001; Haworth, 1997; Jackson, 1999; Martella \& Maass, 2000; Waters \& Moore, 2002). Fryer, however, argued that psychological distress was primarily due to the loss of the manifest benefit of employment (financial income). Past research has found financial strain to be consistently related to lower levels of psychological well-being (Feather, 1989; Rowley \& Feather, 1987) and less access to the latent benefits (Ullah, 1990). These models are not mutually exclusive, with previous studies supporting both models.

It is also now apparent that there is a more complex relationship between access to the latent and manifest benefits of employment and psychological well-being than the direct, linear relationships previously hypothesised. However, in order to test the true nature of the relationship between deprivation of the latent and manifest benefits with psychological distress, researchers need access to more reliable and better validated tools to simultaneously measure the latent and manifest benefits proposed by Jahoda and Fryer. Despite the wide acceptance of Jahoda's and Fryer's theories, there is no “one” complete scale available in the literature to simultaneously test the elements of both of these theories. As such, researchers have used a range of different scales to separately measure each of the latent benefits and manifest benefits (Feather, 1990; Winefield, Tiggemann, Winefield \& Goldney, 1993). This has led to a lack of consistency in the way in which these theories have been empirically 
tested over the past 30 years. Two scales purporting to measure the latent benefits of employment are the Access to Categories of Experience scale (Evans, 1986; originally developed by Miles, 1983) and the Significance of Work Scale (Williams, Morea \& Ives, 1975). Although these scales are popularly used (e.g., Creed, Muller, \& Machin, 2001; Waters \& Muller, 2003), factor testing has raised serious concerns about their psychometric properties and whether they are validly measuring the proposed constructs (see Morrison, Higgins \& Morrison, 2000; Creed \& Macintyre, 2001). For example, exploratory factor analysis of the ACE scale by Creed and Machin (2003) found that it did not demonstrate five separate latent benefits. Waters and Moore’s (2002) results also found that the factor structure of the ACE did not come out according to Evans and Haworth's (1991) original structure.

As such, a strong need exists for a survey that simultaneously measures both the latent and manifest benefits of employment in a reliable and valid way The aims of this study were to develop a scale that (a) measures both the manifest and latent benefits, (b) satisfies professional standards for psychometric adequacy, and (c) presents initial validity evidence in relation to other constructs.

\section{Method: Scale Development Phase}

Scale Development Phase: Item Generation

The aim of this phase was to generate items to form the basis of six unifactorial scales to represent the five latent (Social Contact, Time Structure, Collective Purpose, Enforced Activity and Status) and the one manifest benefit (Financial Strain). We labelled these the Latent and Manifest Benefits (LAMB) scales.

Scale Development Phase: Participants

In this phase, 33 participants were interviewed. These were 16 male (48\%) and 17 female unemployed volunteers, whose ages ranged from 18 to 25 years. All participants were registered as job seekers, recruited from the national employment agency in Australia who 
had experienced substantial periods of unemployment in the previous 12 months. While the range of ages was restricted, these people were targeted due to their experience of the loss of latent and manifest benefits of employment that was the focus of the interviews. At this stage, we were aiming to generate a wide range of items and not assess the impact of reduced access to those benefits on the individual, which could vary across different age groups.

\section{Scale Development Phase: Procedure}

First, semi-structured individual interviews were conducted with these 33 adults. These interviews were undertaken to gain a contemporary understanding of the experiences of unemployment from the participants' own points of view and in their own words. This allowed for a content validation of the latent and manifest benefits model by seeking information from participants on the employment benefits lost as a result of their unemployment experience. The interviews also allowed the latent and manifest benefits to be expressed in the participants' own words, which could then be utilised for the generation of items.. A short interview guide was utilised to ensure that the same general information was covered with each participant.

All interviews were audiotaped and transcribed verbatim for analysis using the Nud*ist (QSR International, 2000) software package. The data were coded according to Jahoda's latent benefits (Social Contact, Time Structure, Collective Purpose, Enforced Activity and Status) and manifest benefits (Financial Strain). For each domain (e.g., Time Structure), several subdomains were identified (e.g., structure imposed by self or others, planned vs unplanned time, time spent productively vs time wasted), and items developed for these. For example, nine items were written for Time Structure (e.g., "I keep busy most of the day”). The authors attempted to ensure that the items were generically worded so that they could be answered not only by unemployed individuals but by other populations, such as students and employed individuals. The items were then phrased as statements representing both access to, and lack 
of, access to the targeted benefit (e.g., "I regularly do things with other people/I rarely do things with other people”). Each item was then attached to a 7-point graphic scale response format. The four authors continued reviewing items until final agreement was obtained on 120 items (20 for each of the five latent and one manifest benefit) using a deductive process to ensure adequate content coverage (Schwab, 1980).

The 120 items were then shown to a small group of academics and doctoral students who had expertise in labour market research. These experts were first asked to rate the relevance of each item to measuring the construct on a 4-point scale of "not at all relevant" to "very relevant”, and second to suggest alternate wording and/or structure for unclear items. Following this process, the four authors then rewrote and deleted some items to finalise an initial listing of 112 items (Social Contact $=20$ items, Time Structure $=19$, Collective Purpose $=19$, Enforced Activity $=17$, Status $=19$, Financial Strain $=18$ ). This final questionnaire was then piloted for language use and readability..

\section{Method: Study 1}

\section{Study 1: Item Reduction}

Using procedures involving the application of classical test theory (Ellis \& Mead, 2002) the goal of Study 1 was to further refine the number of items in each domain to represent independent and unifactorial scales. Two major approaches that may be adopted to conduct item analysis are based on Classical Test Theory (CTT) and Item Response Theory (IRT). The main differences between CTT and IRT are in the model that represents the theory (linear vs nonlinear), the underlying assumptions, and the property of invariance of item and person parameters (Ellis \& Mead, 2002). While tests developed using CTT may have an overall reliability that is adequate, there may be poor measurement precision at some levels of the underlying traits. Therefore, while the procedures reported in this study involve the 
application of CTT to obtain adequate reliability indices, further work is required to determine where, on the underlying trait continuum, each item provides its information.

While some authors suggest that at least 10 items are required for a reliable scale (Kline, 2000), other authors argue that this can be achieved with as few as three (Cook, Hepworth, \& Warr, 1981). Carmines and Zeller (1979) suggest limiting the number of items as the addition of items beyond a critical point makes progressively less impact on internal reliability whilst taking up more of the subject's time. In the present scale development process, the intention was that the scales would be used together, meaning that shorter scales were preferred in order to limit the length of the survey. The final scales were also intended for use with unemployed labour force members, many of whom will not be practiced at filling in forms. Therefore, we sought to reduce the scales so that each contained no more than 10 items as recommended above. In line with Kline (2000), item analysis was conducted first, then followed by exploratory factor analysis.

\section{Study 1: Participants}

Participants were 307 unemployed adults who volunteered to complete a survey containing the 112 scale items and demographic variables. The sample consisted of 178 (58\%) females and 129 (42\%) males, aged between 17 and 55 years, who were receiving unemployment assistance and registered for work with the national employment agency in the central-eastern part of Australia. This sample size exceeds the minimum requirements of 150 observations recommended for exploratory factor analysis (Guadagnoli \& Velicer, 1988; Hair, Anderson, Tatham, \& Black, 1995).

\section{Results: Study 1}

\section{Study 1: Item Analysis}

Two indices were used in the item analysis, inter-item and item-total correlations. Correlation matrices were calculated for each of the five latent and one manifest benefit 
scales. Items that did not correlate with any other scale item or the individual scale total at $\geq$ .3 were discarded. This procedure led to seven items being deleted from the Time Structure scale, one being deleted from each of the Enforced Activity and Financial Strain scales, and no items deleted from the Social Contact, Status and Collective Purpose scales.

\section{Study 1: Factor Analysis}

Following guidelines provided by Kline (2000), the remaining 103 items were subjected to a principal axis factor analysis using an oblique (direct oblimin) rotation. An item was retained within a scale if it loaded $\geq .3$ on one factor alone. Items that had cross or no loadings $(\leq .3)$ were eliminated. For this analysis, the Kaiser-Meyer-Olkin measure of sampling adequacy was .84, indicating the matrix was suitable for factor analysing.

Using the above decision rules, the 103 items were reduced to 77 that loaded on 6 factors, and 4 items that loaded onto a seventh factor. These 77 items were analysed using a second principal axis factor analysis where six factors were rotated in line with the number of scales being developed. Six further items were removed due to cross loadings and failure to load. The remaining 71 items loaded on the six factors, such that there were 15 items for Social Contact items, six for Time Structure, ten for Collective Purpose, 12 for Enforced Activity, 14 for Status, and 14 for Financial Strain. Finally, items were retained if the item-total correlations indicated that removal of that item would increase the Cronbach Alpha internal reliability coefficient. This resulted in a final pool of 36 items that were then subject to a third principal axis factor analysis with oblique rotation of six factors. These 36 items and their factor loadings are reported in Table 1. Eigenvalues, percentage of variance explained, Cronbach’s internal reliabilities, and inter-factor correlations are presented in Table 2.

\section{INSERT TABLES 1 AND 2 ABOUT HERE}

\section{Method: Study 2}

Study 2: Construct, Criterion and Divergent Validity 
Study 1 identified six homogeneous, reliable and theoretically sound scales. Study 2 set out to further test the construct validity of the scales through confirmatory factor analysis conducted on a second separate sample. Once the factor structure had been confirmed, this study sought to examine the criterion and divergent validity of the scales.

\section{Study 2: Participants}

Participants were 250 unemployed people, consisting of 135 (54\%) females and 115 males (46\%), whose ages ranged between $16-68$ years $(M=30.53$; $S D=11.63)$. As in Phase 2, these participants were receiving unemployment assistance and were registered for work with the national employment agency in Australia.

Study 2: Materials

Latent and Manifest Benefits were measured using the 36-item LAMB scale developed in Study 1 . High scores indicate more access to each benefit. The internal reliability coefficients for the scales were .91 (Collective Purpose), .93 (Financial Strain), .92 (Social Contact), .91 (Status), .74 (Time Structure) and .89 (Enforced Activity).

The 12-item version of the General Health Questionnaire (GHQ; Goldberg, 1972) was included as a measure of state negative affectivity. This measure has been widely used and recommended for use as a screening device in occupational settings (e.g., Warr, 1987). Respondents were asked to report on how they felt recently on a range of variables, including cognitive processing, self-esteem, anxiety and depression (e.g., "Have you recently been able to concentrate on whatever you're doing?”). Responses were scored on a four-point scale from zero to three using anchors such as "better than usual/same as usual/less than usual/much less than usual”. Scores were totalled to produce global ratings with a range of 036. Higher scores indicated greater psychological distress. In the present study, the internal consistency coefficient was .92. 
The 12-item Neuroticism scale (EPQ-R: Eysenck \& Eysenck, 1996) was included as a trait measure of trait negative affectivity. Responses were scored one for "yes” and zero for "no", giving a possible range of $0-12$, with higher scores indicating a higher level of neuroticism. The alpha co-efficient for the present study was .81 .

Study 2: Procedure

First, the data for the LAMB scales were subjected to a confirmatory factor analysis (Amos: Arbuckle \& Wothke, 1995) to test for the adequacy of the six-factor model identified in Study 1. Second, to test whether the LAMB scale overlapped with state and trait measures of negative affectivity, the LAMB scales, along with the affective measure of GHQ and the personality measure of neuroticism, were subjected to a further exploratory factor analysis. Third, to further test the construct validity of the LAMB scale, a series of bivariate correlations was calculated between the LAMB scales and the measures of negative affectivity and the demographic variables.

\section{Results: Study 2}

\section{Study 2: Confirmatory Factor Analysis}

The purpose here was to evaluate the six-factor structure of the LAMB scales identified in Study 1 . Each set of six LAMB items that represented an original factor was allowed to load freely on a single latent factor. The correlations among the six latent factors were freely estimated. Variances for all latent factors were fixed at unity to identify the model. Chi-square was $1187.36(579) p<.001 ; \mathrm{NFI}=.95 ; \mathrm{IFI}=.97 ;$ TLI $=.97 ; \mathrm{CFI}=.97 ;$ RMSEA = .07; PCLOSE $=.00$. Hence, the fit indices indicated a satisfactory fit to the six-factor structure of the LAMB scales.

\section{Study 2: Construct Validity}

The degree to which the LAMB scales overlapped with mental health and Neuroticism was tested via a principal axis factor analysis, using a direct oblimin rotation. The Kaiser- 
Meyer-Olkin Measure of Sampling Adequacy (.87) and Bartlett’s Test of Sphericity, $(p<$ .001), indicated the suitability of these data for factor analysis (Hair et al., 1995). Eight factors were rotated (to reflect the six LAMB scales, and the unitary GHQ and Neuroticism scales). This solution was factorially simple and interpretable. All factors had eigenvalues greater than one, and accounted for $69.95 \%$ of the variance. Examination of the pattern matrix indicated that items from the LAMB, GHQ and Neuroticism scales loaded separately onto their respective factors.

Study 2: Relationship between LAMB Scales, measures of Negative Affect, and Demographic Variables

Bivariate correlations were calculated between the six LAMB scales, GHQ, Neuroticism, age, gender and length of unemployment (see Table 3). For the LAMB scales, meaningful correlations (i.e., where the Coefficient of Determination exceeded 10\%) were found between Collective Purpose and Financial Strain and Social Contact, between Social Contact and Status, and between Status and Enforced Activity. All LAMB scales correlated with the state measure of negative affect (GHQ) in the expected direction. Collective Purpose and Financial Strain were meaningfully associated with GHQ, such that the more Collective Purpose and the less Financial Strain, the less psychological distress. None of the LAMB scales were meaningfully associated with the trait measure of Neuroticism, age, gender or length of unemployment. The indications here are that the LAMB scales are largely, though not entirely, independent (indicating construct validity). They relate to affect in the expected way, but are distinct from affect, neuroticism, age, gender and period of unemployment (indicating criterion-related validity).

INSERT TABLE 3 ABOUT HERE 


\section{Discussion}

The results of this study suggest that the newly-developed 36-item Latent and Manifest Benefits (LAMB) scale is reliable and valid. The Cronbach alpha coefficients for the scales ranged from .76 - .93, indicating sound internal reliability for each subscale.

One criticism of the Access to Categories of Experience scale was that some of the scales tapped into affective measures instead of the constructs intended (Creed \& Machin, 2003). However, no overlap was identified between the LAMB scales and negative affectivity, demonstrating discriminant validity for the LAMB scales and indicating their independence from this dimension.

A second criticism of the Access to Categories of Experience scale was that it did not tap all five latent benefits (Creed \& Machin, 2003). Exploratory and confirmatory factor analyses across two large independent sample of unemployed people demonstrated that the LAMB scales reflect six independent, and largely uncorrelated, factors that can be taken to reflect the five latent and one manifest benefit of employment. Bivariate correlations between the LAMB scales and negative affectivity and the demographic variables collected in the study indicate criterion validity, with the LAMB scales demonstrating associations with these variables in the expected directions.

The LAMB scale provides a psychometrically sound assessment that will be valuable for the measurement of the latent and manifest benefits of employment. The provision of subscales allows researchers to test the specific contribution of each of the latent benefits to well being. A small amount of research, using a combination of different scales, hints at there being different weightings of the latent benefits in relation to well-being despite the fact that Jahoda presented them as being of equal weight (Waters \& Moore, 2003; Creed \& Macintyre, 2001). The LAMB scale provides the opportunity to examine the comparative weightings of each of the latent benefits in one comprehensive instrument. This will extend Jahoda's theory, 
as suggested by Waters and Moore (2002), by allowing for a comparison of the weightings of the latent functions. It will also facilitate the opportunity for researchers to test a combined contribution of both Jahoda's and Fryer's theories as suggested by Creed and Macintyre (2001). This will strengthen our understanding of unemployment because it may show that different variables are predictive of well being at various stages of the unemployment cycle or in different sub groups of people such as underemployed, dissatisfied employed, people who are downshifting or having career breaks, or retirees. Some preliminary research with groups who have a different connection with the labour market (eg., low-waged (Hassall, Muller \& Hassall, in press), and unemployed people who have spiritual beliefs (Muller, Creed \& Francis, 2004)) has identified that only specific latent benefits are met in these groups. Given the relationship between latent benefits and psychological well being, the LAMB scale would make it possible to determine those latent benefits not being met and allow practitioners to design interventions to specifically meet their needs in relation to well-being. A better understanding of what contributes to a decline in well being will enable policy makers and practitioners to develop more suitable interventions to address psychological needs.

In conclusion, there has been no one previous scale that is psychometrically sound and measures all of the latent benefits and the manifest benefit. The newly developed LAMB scale is one such instrument and is offered for use in further research.

\section{References}

Arbuckle, J.L., \& Wothke, W. (1995). Amos 4.0 User's Guide. Chicago: Small Waters Corporation.

Carmines, E.G., \& Zeller, R.A. (1979). Reliability and validity assessment. Beverly Hills, CA: Sage. 
Cook, J. D., Hepworth, S. J., \& Warr, P. B. (1981). The experience of work. San Diego: Academic Press.

Creed, P. A., \& Machin, M. A. (2003). Multidimensional properties of the Access to Categories of Experience scale. European Journal of Psychological Assessment, 19, 85-91.

Creed, P. A., \& Macintyre, S. (2001). The relative effects of deprivation of the latent and manifest benefits of employment on the well-being of unemployed people. Journal of Occupational Health Psychology, 6(4), 324-331.

Creed, P. A., Muller, J., \& Machin, M. A. (2001). The role of satisfaction with occupational status, neuroticism, financial strain and categories of experience in predicting mental health in the unemployed. Personality and Individual Differences, 30, 435-447.

Ellis, B. B., \& Mead, A. D. (2002). Item analysis: Theory and practice using classical and modern test theory. In S. G. Rogelberg (Ed.), Handbook of research methods in industrial and organizational psychology (pp. 325-343). Oxford, UK: Blackwell.

Evans, S. T. (1986). Variations in activity and psychological well-being in employed young adults. Unpublished doctoral dissertation, University of Manchester.

Evans, S. T., \& Haworth, J.T. (1991). Variations in personal activity, access to categories of experience and psychological well-being in unemployed young adults. Leisure Studies, 10, 249-264.

Eysenck, H. J., \& Eysenck, S. B. G. (1996). Manual of the Eysenck Personality Scales (EPS-Adult). London: Hodder \& Stoughton Educational.

Feather, N. T. (1989). Reported changes in behaviour after job loss in a sample of older unemployed men. Australian Journal of Psychology, 41(2), 178-185.

Feather, N.T. (1990). The Psychological Impact of Unemployment. Springer Verlag: New York. 
Fryer, D. (1986). Employment deprivation and personal agency during unemployment: A critical discussion of Jahoda's explanation of the psychological effects of unemployment. Social Behaviour, 1(1), 3-23.Goldberg, D. P. (1972). The detection of psychiatric illness by questionnaire. London: Oxford University Press.

Guadagnoli, E., \& Velicer, W.F. (1988). Relation of sample size to the stability of component patterns. Psychological Bulletin, 103, 265-277.

Hair, J., Anderson, R., Tatham, R., \& Black, W. (1995). Multivariate Data Analysis. (4th ed.). New Jersey: Prentice Hall.

Hassall, S., Muller, J., \& Hassall, E. (in press). Working towards ill health? An investigation of psychological well-being in unemployed and employed low-wage earners. International Journal of Employment Studies.

Haworth, J. T. (1997). Work, leisure and well-being. London: Routledge.

Jackson, T. (1999). Differences in psychological experiences of employed, unemployed, and student samples of young adults. Journal of Psychology, 133(1), 49-60.

Jahoda, M. (1981). Work, employment and unemployment: values, theories and approaches in social research. American Psychologist, 36, 184-191.

Kline, P. (2000). The handbook of psychological testing ( $2^{\text {nd }}$ Ed.). London: Routledge.

Martella, D. \& Maass, A. (2000). Unemployment and life satisfaction: The moderating role of time structure and collectivism. Journal of Applied Social Psychology, 30(5), 10951108.

Miles, I. (1983). Adaptation to unemployment. Occasional Paper Series No. 20: Science Policy Research Unit, University of Sussex, Brighton, England.

Morrison, M.A., Higgins, N.C., \& Morrison, T.G. (2000). The factor structure and reliability of a scale measuring the manifest and latent dimensions of employment. Journal of Psychology, 133(3), 349-351. 
Muller, J., Creed, P., \& Francis, L. (2004). Does spirituality mediate the relationship between environmental stressors and psychological wellbeing in distressed unemployed people? Australian Journal of Career Development, 13, 2, 44-54.

Murphy, G. C. \& Athanasou, J. (1999). The effect of unemployment on mental health. Journal of Occupational and Organizational Psychology, 72, 83-99.

QSR International (2000). Nud*ist, Version 4. Doncaster, Victoria: QSR International P/L.

Rowley, K. M., \& Feather, N.T. (1987). The impact of unemployment in relation to age and length of unemployment. Journal of Occupational Psychology, 60, 323-332.

Schwab, D. P. (1980). Construct validity in organization behavior. In B. M. Staw \& L. L. Cummings (Eds.). Research in organizational behavior (Vol. 2). Pp. 3-43. Greenwich, CT: JAI.

Ullah, P. (1990). The association between income, financial strain and psychological wellbeing among unemployed youths. Journal of Occupational Psychology, 63, 317-330.

Warr, P. B. (1987). Work, unemployment and mental health. Oxford: Clarendon Press.

Waters, L. \& Muller, J. (2003). Money or time? Comparing the effects of time structure and financial deprivation on the psychological distress of unemployed adults. Australian Journal of Psychology,55,3, 166-175..

Waters, L. E. \& Moore, K.A. (2002). Reducing latent deprivation during unemployment: The role of meaningful activity. Journal of Occupational and Organizational Psychology, 75(1), 15-32.

Williams, R.S., Morea, P.C., \& Ives, J.M. (1975). The significance of work: An empirical study. Journal of Occupational Psychology, 48, 45-51.

Winefield, A.H., Tiggemann, M., Winefield, H.R., \& Goldney, R.D. (1993). Growing up with unemployment. London: Routledge. 
Table 1

Principal axis factor estimates of the oblique (direct oblimin) factor loadings for the 36-item LAMB scale

Factor

Collective Purpose

1. I usually feel very much a part of my community / I rarely feel very much a part of my community

2. I regularly participate in fundraising events for my church, sporting or community group / I seldom participate in fundraising events for my church, sporting or community group

3. I contribute greatly to my community / I contribute minimally to my community

4. I often feel that I make a meaningful contribution to society / I rarely feel that I make a meaningful contribution to society

5. I often feel a valuable part of society / I seldom feel a valuable part of society

6. I hold a valuable position in society / I do not hold a valuable position in society

Financial Strain

7. My income usually allows me to socialize as often as I like / My income rarely allows me to socialize as often as I like

8. I often have enough money to buy treats for myself / I rarely have enough money to buy treats for myself

9. My income usually allows me to do the things I want / My income rarely allows me to do the things I want

10. My income doesn't restrict me from living as well as my friends / My income restricts me from living as well as my friends

11. From the income I receive I often have money left for savings / From the income I receive I rarely have money left for savings

12. My level of income usually allows me to make plans for the future / My level of income rarely allows me to make plans for the future

\section{$\underline{\text { Social Contact }}$}

13. I regularly engage in social activities with others / I rarely engage in social activities with others

14. I usually spend a lot of time with other people / I rarely spend a lot of time with other people

15. I often meet new people / I seldom meet new people

16. I often go out and meet with others / I rarely go out and meet with others

17. I regularly engage in social activities with people I don't know / I rarely engage in social activities with people I don't know

18. I usually have a lot of opportunities to mix with people / I rarely have a lot of opportunities to mix with people

\begin{tabular}{|c|c|c|c|c|c|}
\hline .76 & -.06 & -.04 & -.06 & .01 & .04 \\
\hline .72 & .01 & -.03 & .13 & -.06 & -.08 \\
\hline .71 & .08 & -.16 & -.02 & .02 & .04 \\
\hline .67 & -.03 & -.01 & -.09 & .07 & .11 \\
\hline .64 & -.04 & .03 & -.21 & .04 & .11 \\
\hline .64 & -.09 & .05 & -.04 & .02 & .05 \\
\hline .01 & -.81 & -.12 & -.07 & -.01 & -.08 \\
\hline-.13 & -.80 & -.01 & -.04 & -.02 & .10 \\
\hline-.06 & -.79 & -.06 & .02 & .00 & .15 \\
\hline .04 & -.76 & -.04 & -.05 & .00 & -.05 \\
\hline .09 & -.76 & .00 & .13 & .02 & -.08 \\
\hline .14 & -.67 & .03 & .09 & -.01 & .06 \\
\hline-.03 & -.01 & -.77 & -.13 & .09 & .02 \\
\hline-.08 & -.09 & -.77 & -.06 & .07 & .01 \\
\hline .01 & -.05 & -.73 & -.02 & -.03 & .01 \\
\hline .06 & -.09 & -.70 & -.05 & -.10 & -.07 \\
\hline .12 & .13 & -.65 & .02 & -.05 & .03 \\
\hline .05 & -.12 & -.63 & .03 & .09 & -.04 \\
\hline
\end{tabular}


$\underline{\text { Status }}$

19. My friends usually value my company / My friends rarely value my company

20. I am often valued by the people around me / I am rarely valued by the people around me

21. I am usually important to my friends / I am rarely important to my friends

22. I often help others / I rarely help others

23. My assistance is greatly welcomed by my family and friends / My assistance is rarely welcomed by my family and friends

24. People often rely on me for help / People rarely rely on me for help

Time Structure

25. I often have nothing to do / I rarely have nothing to do

26. I often wish I had more things to do to fill up the time in my days / I rarely wish I had more things to do to fill up the time in my days

27. I often have a lot of time on my hands / I rarely have a lot of time on my hands

28. There is usually too much spare time in my day / There is rarely too much spare time in my day

29. Time usually drags for me / Time rarely drags for me

30. I usually keep busy most of the day / I rarely keep busy most of the day (Reverse scored)

Enforced Activity

31. I usually do all the things I have to / I rarely do all the things I have to

32. I always catch up with the things I have to do / I rarely catch up with the things I have to do

33. My days are usually well organised / My days are usually not well organised

34. I find it useful to structure my time / I do not find it useful to structure my time

35. I have a good balance in my day between responsibilities and free time / I do not have a good balance in my day between responsibilities and free time

36. I rarely need others to push me to do things / usually need others to push me to do things

$\begin{array}{rrrrrr}-.02 & .04 & -.12 & -.80 & -.06 & .02 \\ -.02 & .13 & -.07 & -.76 & -.07 & .13 \\ .01 & -.06 & -.16 & -.68 & -.01 & -.01 \\ .04 & -.01 & .04 & -.67 & .01 & -.02 \\ & & & & & \\ -.04 & .02 & -.04 & -.62 & .08 & .17 \\ .16 & -.04 & .04 & -.52 & .07 & -.12 \\ & & & & & \\ -.01 & -.02 & -.01 & .08 & .70 & .06 \\ & & & & & \\ .04 & .10 & -.05 & .02 & .68 & -.11 \\ .02 & -.07 & .04 & -.03 & .62 & -.12 \\ .01 & -.02 & .05 & -.18 & .62 & -.02 \\ -.06 & .01 & -.06 & .04 & . \mathbf{6 1} & .14 \\ .10 & -.02 & .01 & .02 & .38 & .29 \\ & & & & & \\ -.03 & -.13 & .17 & -.26 & -.07 & . \mathbf{5 9} \\ .06 & -.07 & .09 & -.17 & -.02 & .59 \\ .21 & -.06 & .06 & .06 & .05 & .55 \\ .04 & .01 & .02 & -.03 & .18 & .52 \\ & & & & & \\ .05 & -.02 & -.14 & .10 & -.08 & . \mathbf{4 7} \\ -.01 & -.03 & -.01 & -.27 & .09 & .38 \\ & & & & & \end{array}$


Table 2

Eigenvalues, percentage of variance explained, Cronbach alpha and the inter-factor correlations for the five latent and one manifest benefit scales

\begin{tabular}{|c|c|c|c|c|c|c|c|c|c|}
\hline \multirow[b]{2}{*}{ Factor } & \multirow[b]{2}{*}{ Eigenvalue } & \multirow{2}{*}{$\begin{array}{l}\text { \% Variance } \\
\text { Explained }\end{array}$} & \multirow[b]{2}{*}{ Alpha } & \multirow[b]{2}{*}{1} & \multirow[b]{2}{*}{2} & \multicolumn{2}{|c|}{ Correlations } & \multirow[b]{2}{*}{5} & \multirow[b]{2}{*}{6} \\
\hline & & & & & & 3 & 4 & & \\
\hline 1. Collective Purpose & 7.50 & 20.84 & .88 & - & -.28 & -.26 & -.18 & .20 & .26 \\
\hline 2. Financial Strain & 3.89 & 10.81 & .92 & & - & .22 & .06 & -.08 & -.24 \\
\hline 3. Social Contact & 3.34 & 9.27 & .89 & & & - & .16 & -.00 & -.00 \\
\hline 4. Status & 2.60 & 7.22 & .84 & & & & - & -.20 & -.27 \\
\hline 5. Time Structure & 2.34 & 6.50 & .78 & & & & & - & .17 \\
\hline 6. Enforced Activity & 1.60 & 4.43 & .76 & & & & & & - \\
\hline
\end{tabular}

Note: Correlation coefficients greater than or equal to .17 are significant at $p<.05$. 
Table 3

Pearson Product-Moment correlations between LAMB scales and GHQ, Neuroticism, Age and Gender; $N=250$

\begin{tabular}{|c|c|c|c|c|c|c|c|c|c|c|c|}
\hline Variables & 1 & 2 & 3 & 4 & 5 & 6 & 7 & 8 & 9 & 10 & 11 \\
\hline 1. Collective Purpose & - & $.36 * * *$ & $.50 * * *$ & $.30 * * *$ & $-.20 * *$ & $.28 * * *$ & $.34 * * *$ & $.21^{* *}$ & -.06 & -.06 & .03 \\
\hline 2. Financial Strain & & - & $.31 * * *$ & -.10 & -.05 & .02 & $.38^{* * *}$ & $.27 * * *$ & $.23 * * *$ & -.01 & $.20^{* *}$ \\
\hline 3. Social Contact & & & - & $.38^{* * *}$ & -.02 & $.21 * *$ & $.32 * * *$ & $.28 * * *$ & $.15^{*}$ & -.06 & $.17^{* *}$ \\
\hline 4. Status & & & & - & $-.19 * *$ & $.63^{* * *}$ & $.14^{* * *}$ & $.13^{*}$ & $.18^{* *}$ & .12 & $.23^{* * *}$ \\
\hline 5. Time Structure & & & & & - & $-.25 * * *$ & $-.18 * *$ & $-.19 * *$ & .08 & -.09 & .03 \\
\hline 6. Enforced Activity & & & & & & - & $.19 * *$ & $.17 * *$ & .03 & .11 & $.18^{* *}$ \\
\hline 7. GHQ & & & & & & & - & $.61^{* * *}$ & $.14^{*}$ & -.08 & .03 \\
\hline 8. Neuroticism & & & & & & & & - & .02 & $-.16^{*}$ & $.13^{*}$ \\
\hline 9. Age & & & & & & & & & - & .06 & $.14^{*}$ \\
\hline 10. Gender & & & & & & & & & & - & .03 \\
\hline 11. Length of Unemployment & & & & & & & & & & & - \\
\hline
\end{tabular}

Note: $*=p<.05,{ }^{* *}=p<.01, * * *=p<.001$. 